\title{
Low Temperature Ductility of Ultrafine Grain $\alpha$ Iron and Its Substitutional Solid Solutions*
}

\section{By Masato ENOMOTO** and Ei-ichi FURUBAYASHI**}

\section{Synopsis}

A study was made of the effect of substitutional solute elements on the ductility of $\alpha$ iron with varied ultrafine grain sizes which was prepared by cold rolling and subsequent annealing to various stages of recovery and recrystallization. The addition of $\mathrm{Si}$ or $\mathrm{Ti}$ was found to have a remarkable effect of improving the low temperature ductility of ultrafine grain recrystallized structure which in an unalloyed condition showed a very small uniform elongation owing to plastic instability; $\mathrm{Al}$ or $\mathrm{Ni}$ was not very effective. $\mathrm{Ni}$ was found to suppress the intergramular fracture which was one of the most important causes of low temperature failure of iron having relatively coarse grain structure.

Lüders strain was also measured; it was found that the critical grain size, $d_{c}$, at which Lüders strain exceeded uniform elongation and the transition from stable to unstable plastic flow occurred, was reduced by substitutional solute elements.

Possible causes for reducing Lüders strain or $d_{c}$ were briefly discussed in terms of slip character and interstitial distribution which were both expected to undergo a considerable change by the presence of those substitutional elements.

\section{Introduction}

Grain refinement is known to be a profitable way to improve strength and toughness of structural steels. It is also considered to be efficient in suppressing grain boundary embrittlement caused by the segregation of impurities by increasing the area of boundary region relative to a given amount of impurities. However, the ductility of ultrafine grain materials is exceedingly poor. ${ }^{1)}$ The principal cause of the worsening of ductility is that ultrafine grain materials tend to undergo an inhomogeneous deformation, and its local strain readily exceeds the maximum strain endurable by work hardening in the initially deformed region. This plastic behavior of ultrafine grain materials is generally called "plastic instability", or "pseudo-brittle fracture ", since the reduction of area is usually large. ${ }^{2-4)}$

It is a well-known fact that the motion of individual dislocations under stress, or the mode of slip in $\alpha$ iron is profoundly influenced by the presence of substitutional solute atoms. Since the slip character has been found by some authors as one of the important factors affecting the inhomogeneous deformation, ${ }^{5)}$ the addition of substitutional elements is expected to have some notable effects on the ductility of ultrafine grain $\alpha$ iron. Numerous data are now available on the strength of substitutional iron alloy. ${ }^{6-8)}$ However, as to the ductility, no systematic studies ${ }^{7,9)}$ have been conducted yet.

In the present study, ultrafine grain structure were developed in ferrite with various kinds of substitutional elements and with various carbon contents by cold rolling and subsequent annealing. Mechanical properties measured were discussed in terms of the improvement of ductility of ultrafine grain $\alpha$ iron.

\section{Experimental Procedure}

A number of substitutional iron alloys with various kinds of solute element such as $\mathrm{Ni}, \mathrm{Si}$, $\mathrm{Ti}$ or $\mathrm{Al}$ were melted in a vacuum induction furnace. Chemical compositions of these alloys are given in Table 1. Each alloy in the series (A) contains $\sim 2 \mathrm{at}^{\%}$ of solute

Table 1. Chemical composition of alloys (wt \%)

\begin{tabular}{|c|c|c|c|c|c|c|c|c|c|c|}
\hline \multicolumn{2}{|c|}{ Alloy } & \multirow{2}{*}{$\frac{\mathrm{Ni}}{0.005}$} & \multirow{2}{*}{$\begin{array}{c}\mathrm{Si} \\
0.009\end{array}$} & \multirow{2}{*}{$\frac{\mathrm{Al}}{0.005}$} & \multirow{2}{*}{$\frac{\mathrm{Ti}}{0.002}$} & \multirow{2}{*}{$\frac{M n}{0.004}$} & \multirow{2}{*}{$\frac{\mathrm{S}}{0.008}$} & \multirow{2}{*}{$\frac{C}{0.010}$} & \multirow{2}{*}{$\frac{N}{0.002}$} & \multirow{2}{*}{$\begin{array}{c}\mathrm{O} \\
0.0017\end{array}$} \\
\hline & $\mathrm{Fe}$ (unalloyed iron) & & & & & & & & & \\
\hline \multirow{4}{*}{ (A) } & $\mathrm{Fe}-2 \% \mathrm{Ni}$ & 2.05 & 0.01 & 0.005 & 0.002 & 0.003 & 0.008 & 0.010 & 0.002 & 0.0015 \\
\hline & $\mathrm{Fe}-1 \% \mathrm{Si}$ & 0.01 & 1.01 & 0.005 & 0.002 & 0.003 & 0.005 & 0.005 & 0.001 & 0.0020 \\
\hline & $\mathrm{Fe}-1 \% \mathrm{Al}$ & 0.01 & 0.01 & 1.06 & 0.002 & 0.003 & 0.005 & 0.007 & 0.002 & 0.0007 \\
\hline & $\mathrm{Fe}-2 \% \mathrm{Ti}$ & 0.01 & 0,01 & 0.05 & 1.96 & 0.003 & 0.005 & 0.009 & 0.002 & 0.0024 \\
\hline \multirow{3}{*}{ ( B ) } & $\mathrm{Fe}-0.5 \% \mathrm{Si}$ & 0.01 & 0.49 & 0.005 & 0.002 & 0.003 & 0.005 & 0.010 & 0.002 & 0.0040 \\
\hline & $\mathrm{Fe}-2 \% \mathrm{Si}$ & 0.01 & 2.00 & 0.005 & 0.002 & 0.003 & 0.005 & 0.007 & 0.002 & 0.0025 \\
\hline & $\mathrm{Fe}-2 \% \mathrm{Ni}-1 \% \mathrm{Si}$ & 1.98 & 0.95 & 0.005 & 0.002 & 0.003 & 0.005 & 0.009 & 0.002 & 0.0029 \\
\hline \multirow{2}{*}{ (C) } & $\mathrm{Fe}-1 \% \mathrm{Si}-0.05 \% \mathrm{C}$ & 0.01 & 1.00 & 0.005 & 0.002 & 0.003 & 0.005 & 0.048 & 0.002 & 0.0029 \\
\hline & $\mathrm{Fe}-1 \% \mathrm{Si}-0.1 \% \mathrm{C}$ & 0.01 & 1.03 & 0.005 & 0.002 & 0.003 & 0.005 & 0.095 & 0.002 & 0.0032 \\
\hline \multirow{3}{*}{ (D) } & $\mathrm{Fe}$ & & \multirow{3}{*}{\multicolumn{3}{|c|}{ Wet-hydrogen treated }} & \multicolumn{5}{|c|}{$<0.001$} \\
\hline & $\mathrm{Fe}-2 \% \mathrm{Ni}$ & & & & & \multicolumn{5}{|c|}{0.002} \\
\hline & $\mathrm{Fe}-1 \% \mathrm{Si}$ & & & & & \multicolumn{5}{|c|}{0.002} \\
\hline
\end{tabular}

* Originally published in Tetsu-to-Hagané, 63 (1977), 469, in Japanese. English version received February 23, 1977.

** National Research Institute for Metals, Nakameguro, Meguro-ku, Tokyo 153. 
atoms. The content of $\mathrm{Si}$ was varied in the series (B), which also includes one alloy containing $\sim 2$ at $\%$ each of $\mathrm{Ni}$ and $\mathrm{Si}$ simultaneously. In order to maintain grain boundary cohesion at low temperatures, the carbon content of alloys in the series (A) and (B) was adjusted to $\sim 0.01 \mathrm{wt}^{\circ} \%$ by adding an amount more than required to deoxidize the electrolytic iron on melting.

Carbon content was varied in the series (C) and (D). In the series (D) the carbon content was reduced by a wet-hydrogen treatment at $700^{\circ} \mathrm{C}$ for 3 days of the hot-rolled sheets of alloys in the series (A).

The $10 \mathrm{~kg}$ heats of every alloy were, after homogenization at $1200^{\circ} \mathrm{C}$ for $2 \mathrm{hr}$, forged and hot-rolled into $3.5 \mathrm{~mm}$ thick sheet, then air-cooled. They were cold-rolled by a reduction from 55 to $90 \%$ and annealed for $1 \mathrm{hr}$ at various temperatures between room temperature and $950^{\circ} \mathrm{C}$, by which various microstructures were developed ranging from deformed to recrystallized states. In order to avert possible effects of sub-boundaries formed on $\gamma-\alpha$ transformation during cooling, annealing was confined to $\alpha$ region except for the alloys in the series (C), in which annealing was carried out in the $(\alpha+\gamma)$ two-phase region for some specimens. After the annealing specimens were aircooled and held in a bath of dry ice-alcohol to minimize the effect of aging by interstitial solute atoms.

The sheet tensile specimens with $3 \mathrm{~cm}$ gauge length, the thickness of which was always greater than 6 to 7 times the grain size, were strained using an Instrontype machine at a strain rate of $3 \times 10^{-4} \mathrm{sec}^{-1}$ at $23^{\circ}$, $-78^{\circ}$ and $-196^{\circ} \mathrm{C}$.

\section{Results}

\section{Microstructure}

In Fig. 1 areal fractions recrystallized and sizes of recrystallized grains and subgrains of $90 \%$ coldrolled $\mathrm{Fe}$ and $\mathrm{Fe}-2 \% \mathrm{Ni}$ are plotted against the annealing temperature. The annealing time was $1 \mathrm{hr}$. Completely recrystallized structures were obtained at temperatures higher than $700^{\circ} \mathrm{C}$ for $\mathrm{Fe}$ and $600^{\circ} \mathrm{C}$ for $\mathrm{Fe}-2 \% \mathrm{Ni}$. A typical appearance of partially recrystallized structure of $\mathrm{Fe}-2 \% \mathrm{Ni}$ which was coldrolled by $90 \%$ and annealed at $480^{\circ} \mathrm{C}$ for $1 \mathrm{hr}$ is shown in Photo. 1, the areal fraction recrystallized being about $60 \%$. The microstructure is composed of subgrains smaller than $1 \mu \mathrm{m}$ and recrystallized grains of $2 \sim 3 \mu \mathrm{m}$ size. Below $400^{\circ} \mathrm{C}$ no recrystallized grains were observed. When the areal fraction reached $100 \%$, the mean sizes of recrystallized grains were increased to $12 \sim 13 \mu \mathrm{m}$ for $\mathrm{Fe}$ and $7 \sim 8 \mu \mathrm{m}$ for $\mathrm{Fe}-$ $2 \% \mathrm{Ni}$, respectively.

Microstructures consisting of grains smaller than $10 \mu \mathrm{m}$ are customarily called ultrafine grain structure. In this report, partially recrystallized fine structures containing many sub-boundaries will also be designated as an ultrafine structure, although the contribution of such sub-boundaries to plastic flow may be considerably different from that of well-defined high angle boundaries in a completely recrystallized structure.

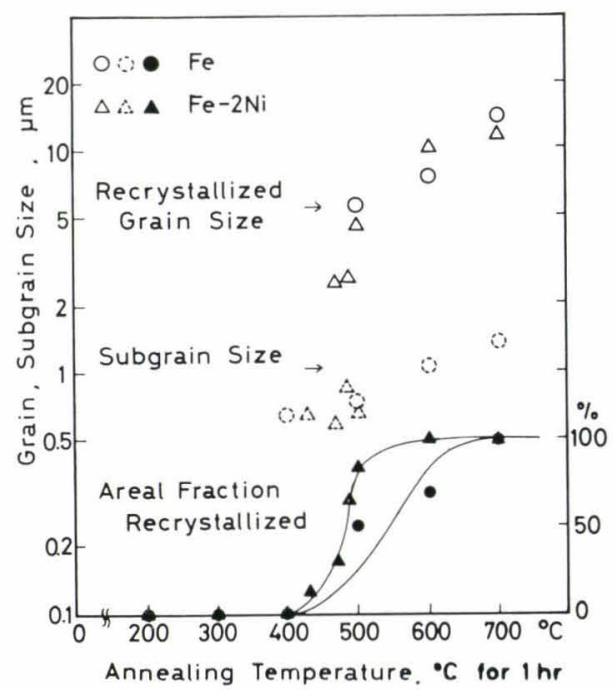

Fig. 1. Recrystallized grain size, subgrain size and areal fraction recrystallized of $90 \%$ cold-rolled $\mathrm{Fe}$ and $\mathrm{Fe}-$ $2 \% \mathrm{Ni}$ as a function of annealing temperature

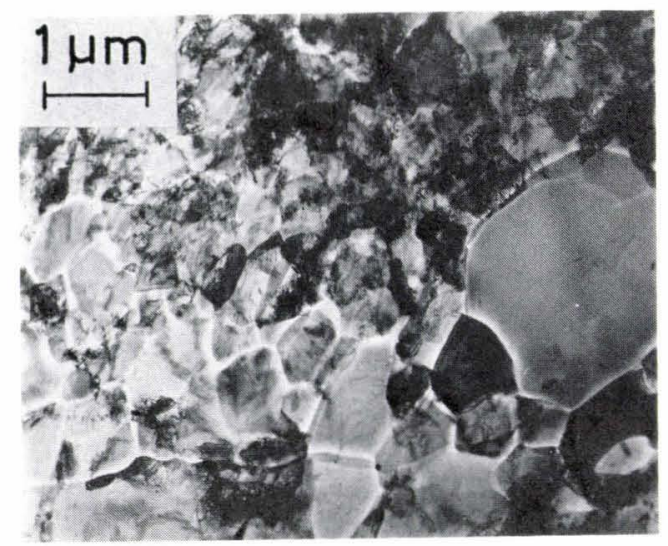

Photo. 1. Transmission electron micrograph of partially recrystallized structure which was obtained by annealing the $90 \%$ cold-rolled $\mathrm{Fe}-2 \% \mathrm{Ni}$ alloy at $480^{\circ} \mathrm{C}$ for $1 \mathrm{hr}$

\section{Load-elongation Curves}

In Figs. 2 (a) to (f) typical examples of nominal stress (load divided by original area) vs. elongation curves of $\mathrm{Fe}, \mathrm{Fe}-2 \% \mathrm{Ni}$ and $\mathrm{Fe}-1 \% \mathrm{Si}$ tested at $23^{\circ}$ and $-196^{\circ} \mathrm{C}$ are shown. The curve marked with "D " corresponds to deformed state, the curve " $\mathrm{P}$ " to partially recrystallized state, the curve " $\mathrm{F}$ " to a state completely recrystallized into fine grains $(\$ 20 \sim$ $30 \mu \mathrm{m})$, and the curve " $\mathrm{C}$ " to that completely recrystallized into relatively coarse grains $(\geq 20 \sim 30 \mu \mathrm{m})$.

The three alloys showed a similar tensile behavior at $23^{\circ} \mathrm{C}$; at $-196^{\circ} \mathrm{C}$, however, they presented several distinctively different features. First of all, $\mathrm{Fe}-1 \% \mathrm{Si}$ specimens of partially recrystallized $(\mathrm{P})$ or completely recrystallized structure of fine grain size $(\mathrm{F})$ had an elongation far larger compared with that of the other two alloys in the same structure. The load-elongation curves of $\mathrm{Fe}$ and $\mathrm{Fe}-2 \% \mathrm{Ni}$ specimen of the corresponding state were typical of plastic instability, i.e., continuing decrease of load due to rapid decrease in cross sectional area after the yielding. On the other 

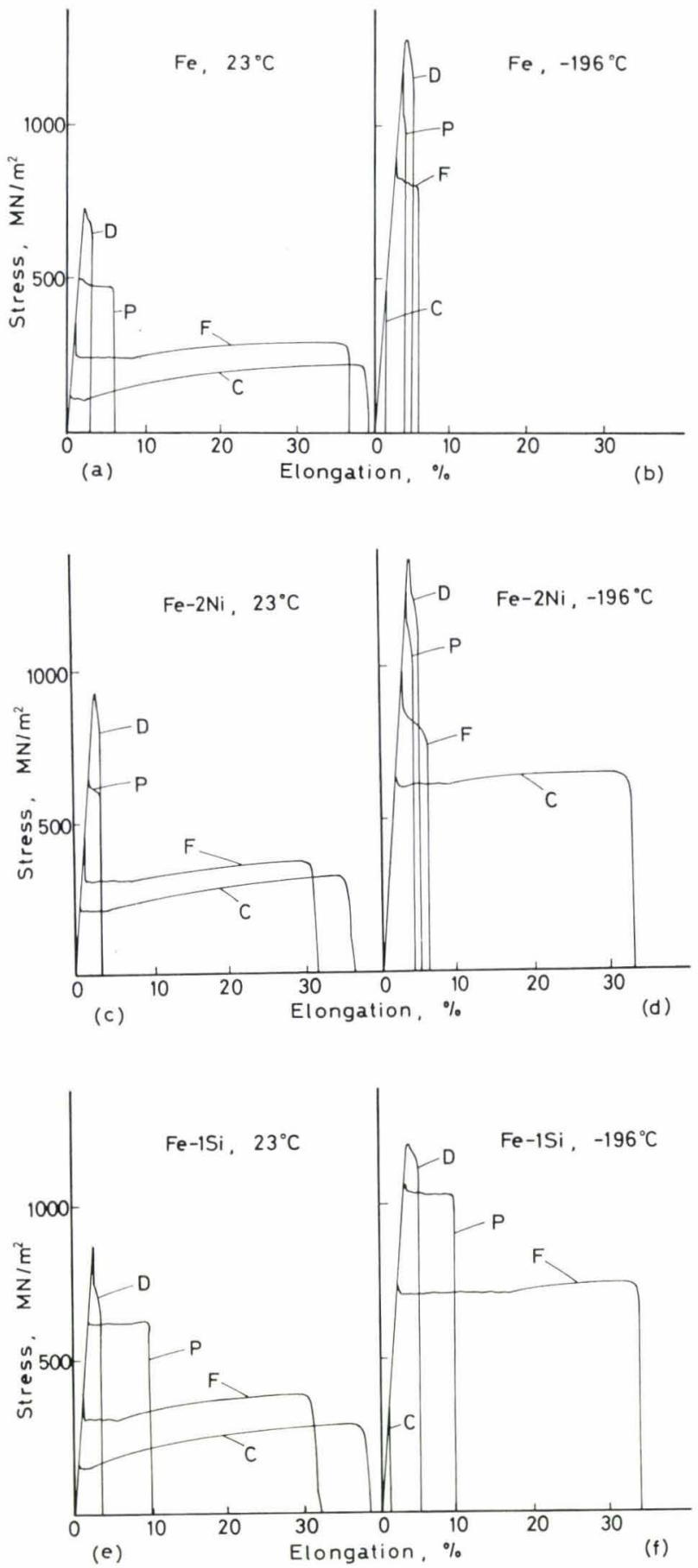

Fig. 2. Nominal stress-elongation curves at various stages of recovery and recrystallization. D, P, F and C: denote deformed state, partially recrystallized state, completely recrystallized state of fine $(\$ 20 \sim 30 \mu \mathrm{m})$ and relatively coarse grain size, respectively.

hand, the $\mathrm{Fe}-1 \% \mathrm{Si}$ specimen of (F) state exhibited normal tensile behavior, i.e., sharp yield drop, Lüders deformation and subsequent work hardening.

Secondly, $\mathrm{Fe}$ and $\mathrm{Fe}-1 \% \mathrm{Si}$ specimen of completely recrystallized state of coarse grain size (C) fractured in a brittle manner before yielding occurred, whereas $\mathrm{Fe}-2 \% \mathrm{Ni}$ specimen of the corresponding state was of a large elongation. The fracture surface of $\mathrm{Fe}$ and $\mathrm{Fe}-1 \% \mathrm{Si}$ specimen was mostly intergranular with a small fraction of grains exposing cleavage facets.

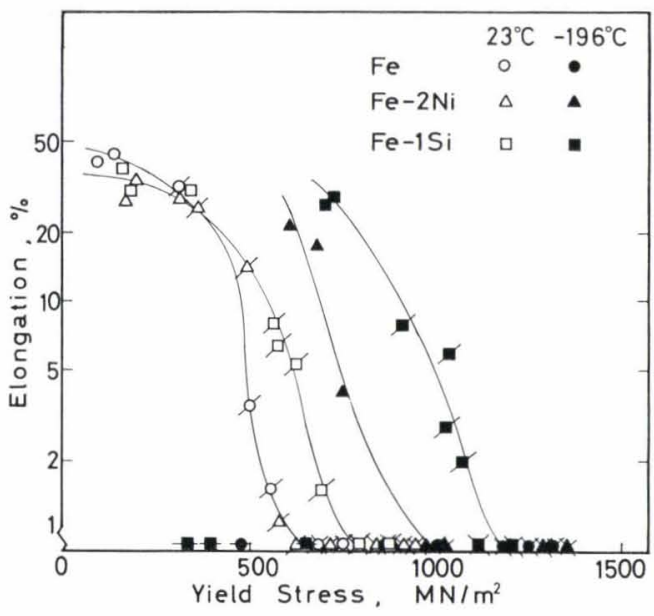

Fig. 3. Strength-ductility relationships of $\mathrm{Fe}, \mathrm{Fe}-2 \% \mathrm{Ni}$ and $\mathrm{Fe}-1 \% \mathrm{Si}$ with heavily deformed $(x)$, partially (/) and completely recrystallized structure. The brittle specimens are marked with a horizontal line $(-)$.

\section{Relationship between Strength and Ductility}

In Fig. 3 the relationships between strength and ductility of $\mathrm{Fe}, \mathrm{Fe}-2 \% \mathrm{Ni}$ and $\mathrm{Fe}-1 \% \mathrm{Si}$ alloys are shown, taking the lower yield strength and the uniform elongation as the measure of strength and ductility, respectively. Both vary according to the annealing temperature. In the figure, the partially recrystallized structures $(\mathrm{P})$ are marked with a short oblique line ( $/$ ) and the deformed structures (D) with a small cross $(x)$, while those specimens which fractured in a brittle manner before yielding are marked with a short horizontal line (-), all superimposed on the corresponding data points.

At $23^{\circ} \mathrm{C}$, recovery and recrystallization caused a rapid increase in uniform elongation as well as a decrease in lower yield strength in a similar manner for the three alloys. At $-196^{\circ} \mathrm{C}$, however, the strengthductility relationships were varied depending on the solute element. Namely, whereas Fe specimens showed substantially no ductility in any state from deformed to completely recrystallized, $\mathrm{Fe}-2 \% \mathrm{Ni}$ and $\mathrm{Fe}-1 \% \mathrm{Si}$ specimens gave rise to a large elongation over a certain range of the annealing temperature. For $\mathrm{Fe}-2 \% \mathrm{Ni}$, for example, specimens in the completely recrystallized state with coarse grain size had a large uniform elongation, although specimens in the state from deformed to partially recrystallized showed very poor ductility. For $\mathrm{Fe}-1 \% \mathrm{Si}$, on the other hand, a substantial elongation was obtained when in a fine grained state from partially to completely recrystallized, though the ductility was reduced, finally to zero, owing to grain boundary embrittlement as the recrystallized grain size was increased. A more desirable combination of strength and ductility was obtained at low temperatures for $\mathrm{Fe}-1 \% \mathrm{Si}$ than for $\mathrm{Fe}-2 \% \mathrm{Ni}$.

The grain size dependences of uniform elongation of $\mathrm{Fe}, \mathrm{Fe}-2 \% \mathrm{Ni}$ and $\mathrm{Fe}-1 \% \mathrm{Si}$ at $23^{\circ},-78^{\circ}$ and $-196^{\circ} \mathrm{C}$ are given in Figs. 4 (a) to (c). Although the points in Fig. 3 represent only those specimens that were cold-rolled by more than $75 \%$, in Fig. 4 the points 

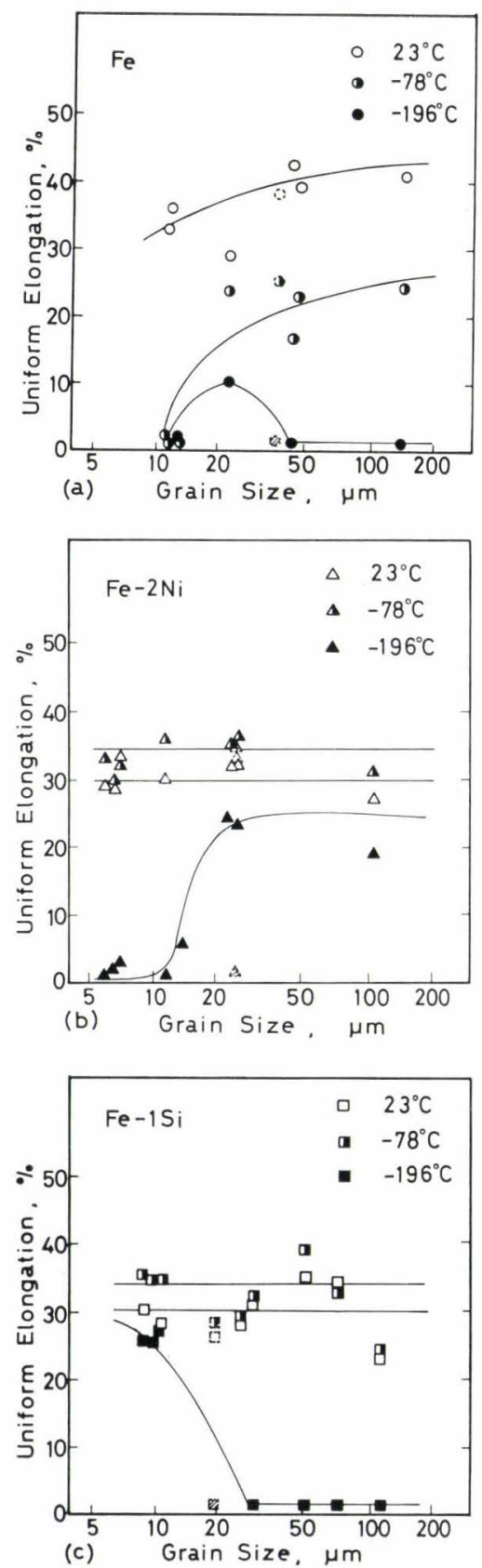

Fig. 4. Uniform elongation as a function of ferrite grain size. Dotted marks correspond to wet-hydrogen treated materials.

of the specimens with lower rolling reduction are included: grain size ranges larger than $50 \mu \mathrm{m}$ for Fe or $\mathrm{Fe}-1 \% \mathrm{Si}$ and larger than $25 \mu \mathrm{m}$ for $\mathrm{Fe}-2 \% \mathrm{Ni}$ were obtained from relatively low rolling reductions. The points corresponding to deformed or partially recrystallized states are omitted. Dotted marks are for decarburized materials in completely recrystallized state obtained by cold rolling by $90 \%$ and annealing at $700^{\circ} \mathrm{C}$ after the wet-hydrogen treatment.

For Fe, specimens of a grain size smaller than $23 \mu \mathrm{m}$ (at this grain size the specimen exhibited $\sim 10 \%$ elongation) fractured by necking, while specimens of a grain size larger than this fractured intergranularly. The addition of $2 \% \mathrm{Ni}$ was found to suppress the intergranular fracture in coarse grained specimens, although it has very little effect of prevent- ing the occurrence of unstable necking in fine grained specimens. On the contrary, the addition of $1 \% \mathrm{Si}$ had a remarkable effect of improving the low temperature ductility in fine grained specimens, while coarse grained specimens fractured intergranularly as Fe specimens of coarse grain size did. Fe specimens of 11 to $14 \mu \mathrm{m}$ grain size exhibited strong plastic instability even at $-78^{\circ} \mathrm{C}$. This unstable flow was improved by $2 \% \mathrm{Ni}$ addition, not to mention the $1 \% \mathrm{Si}$ addition.

The well-known effect of $\mathrm{Ni}$ on the ductility and toughness of steels has generally been attributed to the suppression of the initiation of cleavage fracture at low temperatures. The present result is, however, that the improvement effect was achieved by the suppression of intergranular fracture in relatively coarse grained ferrite. The present authors intend to discuss this observation in a separate paper.

Since the addition of $\mathrm{Si}$ to an amount in excess of that required for deoxidization on melting has long been believed to have a detrimental effect on the ductility of ferrite, very few investigations are report$\mathrm{ed}^{11-13)}$ on the basis of an expectation that Si should exert a valuable effect on the ductility of ferrite. In this study, it has been found that Si actually has an effect of improving the ductility of fine grained ferrite through preventing the plastic instability, and that it manifests its good effect especially at low temperatures. ${ }^{14)}$

\section{Lüders Strain}

Plastic instability is caused by an accumulation of strain in a narrow localized region. The amount of an accumulated strain can be adequately described by Lüders strain. Dependences of Lüders strain, i.e., the strain at the termination of constant load extension, on ferrite grain size at $23^{\circ}$ and $-78^{\circ} \mathrm{C}$ are shown in Fig. 5. It should be mentioned that the load was not always constant during Lüders deformation in large grained specimens. The formation of additional Lüders bands, which readily occurred in large grained specimens, caused a stress drop, and the junction of Lüders fronts propagating in opposite directions caused a sudden increase in stress. This is because the change in the number of Lüders bands caused by the junction or annihilation may cause the change in the number of dislocations which can participate in deformation, as has already been pointed out. ${ }^{15,16)}$ The Lüders strain has been described to be a function of the stress at which Lüders front propagates. Consequently, special care should be taken to restrict the nucleation of additional bands for an accurate determination of Lüders strain. In the present study, no correction was made with regard to this, since the change in the propagation stress was observed only in a few specimens of large grain size.

As is obvious from Fig. 5, both the decrease in ferrite grain size and in deformation temperature caused the increase of Lüders strain. It should be noted that the addition of $\mathrm{Ni}$ or $\mathrm{Si}$ had the effect of reducing the Lüders strain of ferrite over a range of fine grain size. While the difference among the alloys was small 


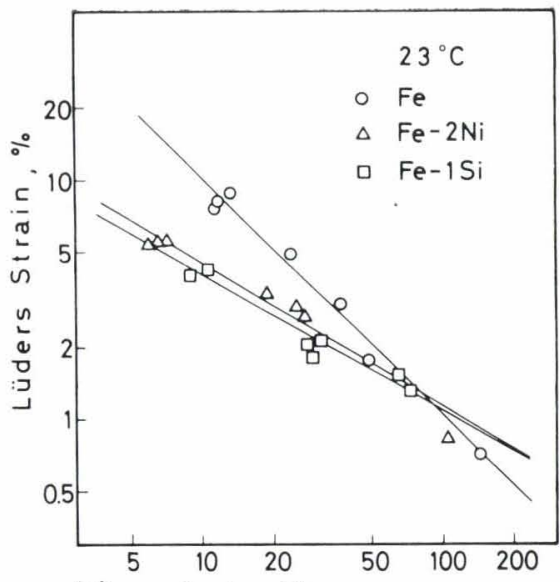

(a)

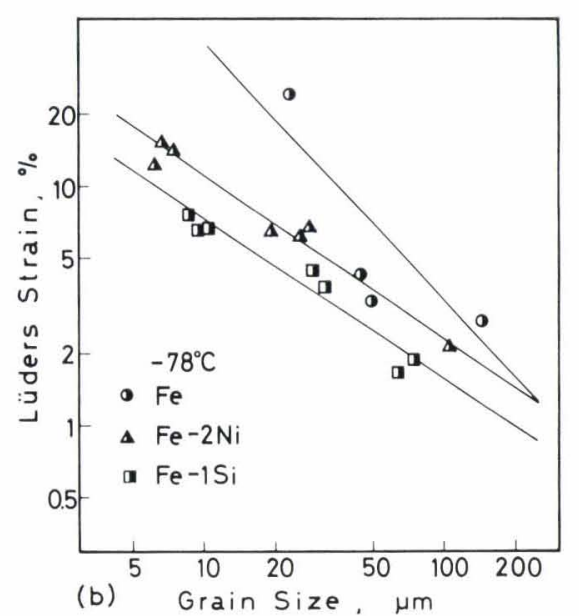

Fig. 5. Dependences of Lüders strain on ferrite grain size

at $23^{\circ} \mathrm{C}$, it became large as the deformation temperature was decreased, i.e., the Lüders strain was decreased in the order of $\mathrm{Fe}, \mathrm{Fe}-2 \% \mathrm{Ni}$ and $\mathrm{Fe}-1 \% \mathrm{Si}$ when compared at the same grain size.

Figure 6 shows the relationships between the Lüders strain and the lower yield strength (or the stress at which Lüders front propagates) of the three alloys. The addition of $\mathrm{Ni}$ or $\mathrm{Si}$ was also found to cause the decrease in Lüders strain when compared at the same strength.

This effect of substitutional elements on Lüders strain seems to be closely related to the effect of improving the low temperature ductility of fine grained materials mentioned earlier.

\section{Effect of Si Content}

The strength-ductility relationships of the alloys with $0.5 \%, 1 \%$ and $2 \% \mathrm{Si}$ are shown in Fig. 7. All the specimens of $\mathrm{Fe}-0.5 \% \mathrm{Si}$ exhibited plastic instability except for the specimen of the largest grain size. Consequently, it may be concluded that the addition of $0.5 \% \mathrm{Si}$ is almost inefficient in improving the low temperature ductility. The addition of $2 \% \mathrm{Si}$ was found to have an improvement effect to nearly the same extent as the addition of $1 \% \mathrm{Si}$.

In Fig. 7 the points of $\mathrm{Fe}-2 \% \mathrm{Ni}-1 \% \mathrm{Si}$ are also included. The simultaneous addition of $\mathrm{Ni}$ and $\mathrm{Si}$ did not give rise to any injury on the ductility at low tem-

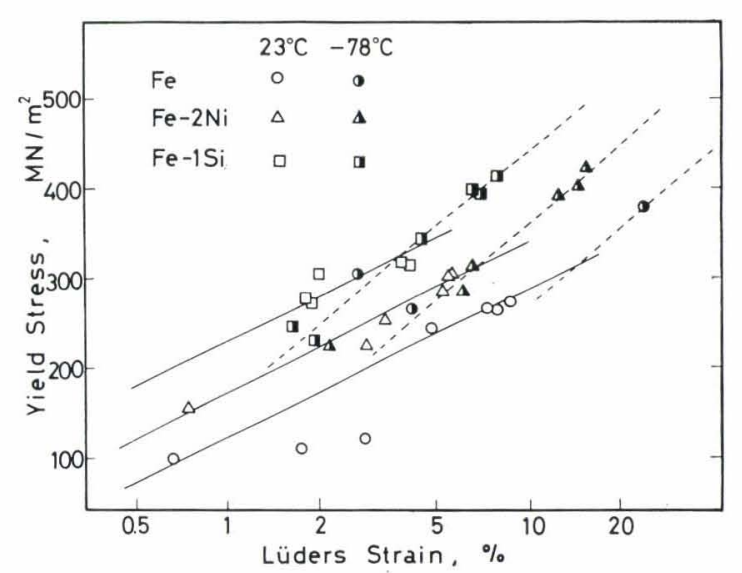

Fig. 6. Relationships between lower yield strength and Lüders strain. Experimental points are confined to completely recrystallized structure.

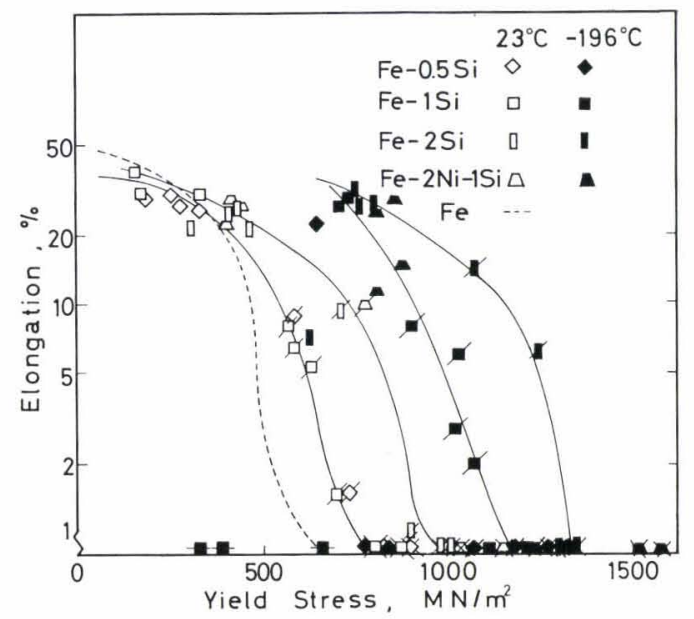

Fig. 7. Strength-ductility relationships of $\mathrm{Fe}-\mathrm{Si}$ alloy with various Si contents. Data of the alloy added with $2 \mathrm{at}^{\circ} \mathrm{Ni}$ and Si simultaneously are also included.

peratures. On the contrary, the strength at $23^{\circ} \mathrm{C}$ was rather higher than the $\mathrm{Fe}-2 \% \mathrm{Si}$ alloy; they are almost equal in total solute content $(\sim 4 \mathrm{at} \%)$.

Several investigations have already been documented on the effect of substitutional solute elements on the ductility and toughness at low temperatures. The common interpretations are that the lowering of ductile-to-brittle-transition-temperature (D.B.T.T.) was caused by the strong interaction between substitutional and interstitial solute elements. ${ }^{17,18)}$ According to those results, the minimum in transition temperature occurred at a solute content of $\sim 1 \%$ or less, and the D.B.T.T. was increased as the solute content exceeded $\sim 1 \%$. Such solute content dependence is apparently different from that of the present findings, suggesting that some basic effect of solute atoms on dislocation mechanism as well as substitutional and interstitial solute interaction is responsible for the effect of Si mentioned above.

\section{Effect of C Content}

Strength-ductility relationships of $\mathrm{Fe}-1 \% \mathrm{Si}$ alloy with various carbon contents from 0.002 to $0.1 \%$ are 
given in Fig. 8. The specimens of partially recrystallized structure with $0.002 \% \mathrm{C}$ were of a large elongation. The ductility was almost maintained up to $0.1 \%$ C. A few specimens with higher carbon contents annealed at temperatures higher than $700^{\circ} \mathrm{C}$ showed uniform elongation of less than $10 \%$.

The microstructures with 0.05 and $0.1 \% \mathrm{C}$ were mostly equiaxed single phase structure, whose grain size did not exceed $10 \mu \mathrm{m}$, much finer than the materials with $0.01 \% \mathrm{C}$. Cementite and other transformation products from austenite were observed at ferrite grain boundaries in the specimen annealed at $900^{\circ} \mathrm{C}$.

\section{Effect of $\mathrm{Al}$ and $\mathrm{Ti}$}

In order to see if any other element having the same effect as $\mathrm{Si}$ exists, tensile tests were conducted in the alloys with each $2 \mathrm{at} \% \mathrm{Al}$ or $\mathrm{Ti}$. The results are shown in Fig. 9. The low temperature ductility of $\alpha$ iron was scarcely improved by the addition of $1 \% \mathrm{Al}$; the uniform elongation of $\mathrm{Fe}-1 \% \mathrm{Al}$ specimen was as small as that of $\mathrm{Fe}$ specimen in the state from partially to recrystallized. Unstable necking was the main cause

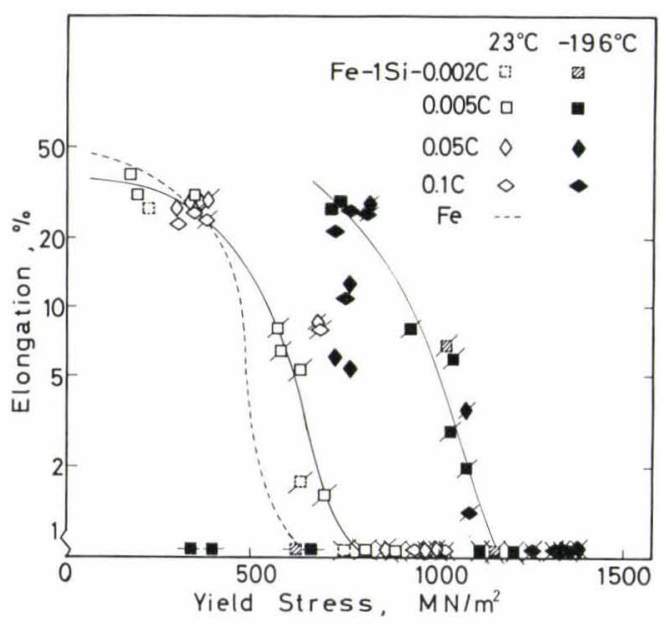

Fig. 8. Strength-ductility relationships of $\mathrm{Fe}-1 \% \mathrm{Si}$ alloy with various carbon contents

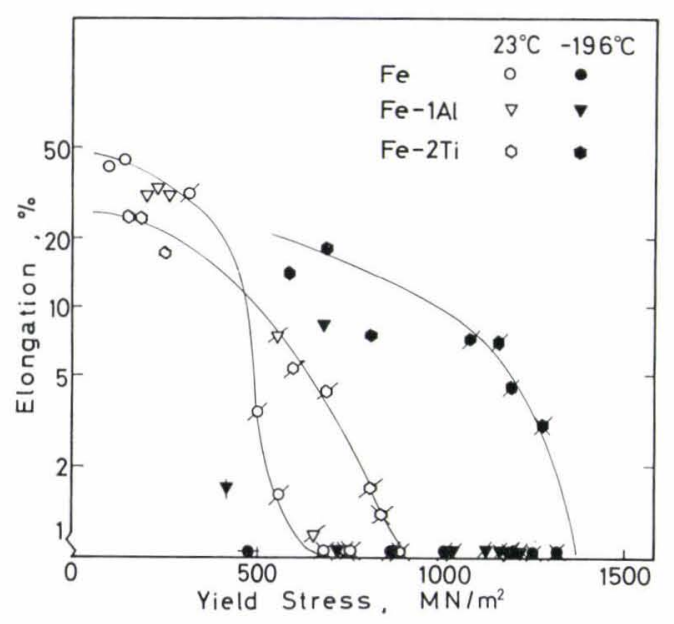

Fig. 9. Strength-ductility relationships of $\mathrm{Fe}, \mathrm{Fe}-1 \% \mathrm{Al}$ and $\mathrm{Fe}-2 \% \mathrm{Ti}$ of the poor ductility even in coarse grained specimens. The specimen with a maximum of $112 \mu \mathrm{m}$ grain size was fractured after the repetition of large stress drop two or three times by twinning. In the figure, the specimen in which a stress drop by twinning was observed on load-elongation curve is marked with a short vertical line $(\mid)$.

For $\mathrm{Fe}-2 \% \mathrm{Ti}$, flow stress at $23^{\circ} \mathrm{C}$ continued to increase with strain until the ultimate tensile stress was attained. At $-196^{\circ} \mathrm{C}$, a small yield drop was observed. A few of those specimens exhibited constant load extension over a range of initial strain. On the whole, Lüders strain of $\mathrm{Fe}-2 \% \mathrm{Ti}$ was so small that the inhomogeneity of deformation was hardly recognized. As is shown from the figure, the effect of $\mathrm{Ti}$ addition is conspicuous especially in recovered or partially recrystallized state.

It should be noted that the uniform elongation of $\mathrm{Fe}-2 \% \mathrm{Ti}$ specimen of partially recrystallized structure at $23^{\circ} \mathrm{C}$ is a little larger than that of $\mathrm{Fe}$ or $\mathrm{Fe}-1 \% \mathrm{Al}$ specimen of the corresponding structure. The same is the case with $\mathrm{Si}$; the room temperature ductility of partially recrystallized structure of $\mathrm{Fe}-1 \% \mathrm{Si}$ is better than that of $\mathrm{Fe}$ or $\mathrm{Fe}-2 \% \mathrm{Ni}$. In this way, the effect of $\mathrm{Si}$ or Ti on the ductility of ferrite was found to appear even at ambient temperature, becoming more distinct as the deformation temperature was decreased.

\section{Discussion}

As indicated above, the deformation of ultrafine grain materials is characterized by very poor ductility owing to plastic instability, which is considered to occur when

$$
\varepsilon_{L} \geqq \varepsilon_{U}
$$

here, $\varepsilon_{L}$ denotes Lüders strain which usually increases as the grain size of materials decreases and $\varepsilon_{V}$ denotes uniform elongation. ${ }^{1)}$

As was shown in Fig. 5, grain size dependence of Lüders strain is profoundly influenced by deformation temperature and by the presence of substitutional solute element. In Fig. 10, the uniform elongation and Lüders strain of $\mathrm{Fe}-1 \% \mathrm{Si}$ is shown as a function of ferrite grain size. It is obvious from the figure that Eq. (1) is always satisfied at a grain size smaller than a certain critical value denoted as $d_{c}$. At $d_{c}$, a ductility transition occurs from the normal tensile behavior exhibiting sharp yield drop, Lüders deformation and homogeneous work hardening, to the unstable plasticity behavior which causes necking immediately after yielding takes place. It is apparent that $d_{c}$ shifts to coarser grain size side as the deformation temperature is decreased. This means, in other words, that the critical deformation temperature at which the ductility transition occurs is lowered as the grain size of materials is decreased, as has already been pointed out by W. B. Morrison. ${ }^{2)}$

The $\varepsilon_{U}$ was found to be almost independent over the whole grain size range studied, as indicated in Fig. 4. In Fig. 10 linear extrapolation was adopted to determine $d_{c}$. Some authors have shown that the 


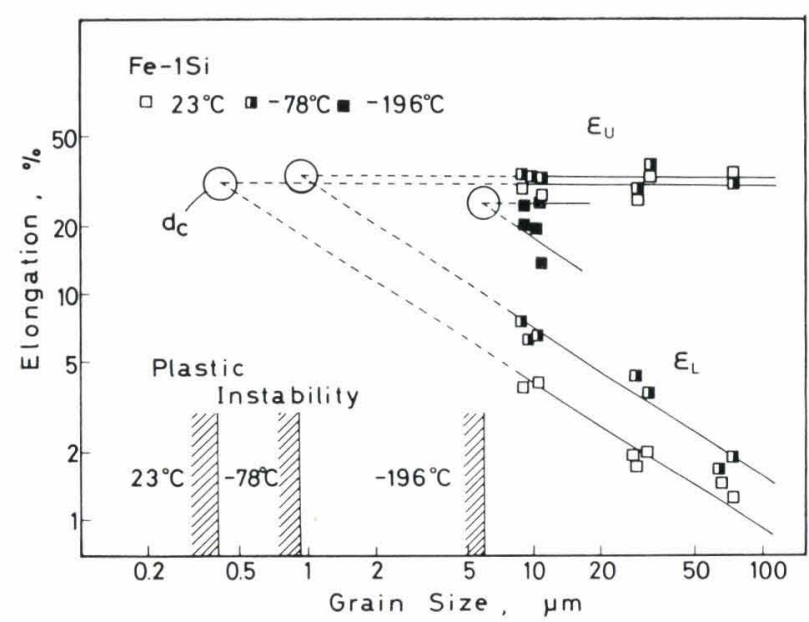

Fig. 10. Schematic diagram for the determination of critical grain size at which a ductility transition occurs. The $\varepsilon_{L}$ and $\varepsilon_{U}$ denote Lüders strain and uniform elongation, respectively. The region in which plastic instability occurs is extended to larger grain size as deformation temperature is decreased.

uniform elongation rapidly decreases as the grain size is reduced to ultrafine grain size range $(\lesssim 10 \mu \mathrm{m}){ }^{1)}$ This may be attributed to the fact that for ultrafine grain materials, in which the mean free path of dislocations can reasonably be assumed to be equal to grain diameter, more dislocations have to be stored in individual grains to undergo a given amount of strain compared with materials of large grain size. The decrease in uniform elongation over a fine grain size range apparently causes the shift of the intersection of the two extrapolation lines to a larger grain size. However, the correction of $d_{c}$ seems to be rather small.

The $d_{r}$ values of the present alloys are given in Table 2. It will be seen that $d_{c}$ is decreased by the addition of substitutional element. In particular, the decrease in $d_{c}$ of alloys with Si or Ti is remarkable.

The value of $d_{c}$ was also found to increase as the strain rate was raised. In fact, the $\mathrm{Fe}-2 \% \mathrm{Ni}$ specimen of $7 \mu \mathrm{m}$ grain size exhibited plastic instability at the strain rate of $3 \times 10^{-1} \mathrm{sec}^{-1}$ at $23^{\circ} \mathrm{C}$.

As stated above, occurrence of unstable plasticity which ultrafine grain ferrite readily exhibits at low temperatures and its suppression by solute elements are both conveniently described by the change of critical grain size, $d_{c}$.

In the following, a few points will be discussed about a factor affecting Lüders strain or $d_{c}$. The first point to be considered is that in the presence of substitutional solute element the distribution of interstitials such as $\mathrm{C}$ and $\mathrm{N}$, which are known to have a great influence on Lüders deformation, ${ }^{19)}$ is changed. The observed homogeneous deformation of $\mathrm{Fe}-2 \% \mathrm{Ti}$ specimen may be due to the so-called scavenging effect of interstitials by $\mathrm{Ti}$ atoms. As for $\mathrm{Si}$, a few specimens of $\mathrm{Fe}-1 \% \mathrm{Si}$ alloy showed no yield drop, while an initiation of constant load extension was well defined on the load-elongation curve. The similar behavior is often observed with single crystals of $\mathrm{Fe}-\mathrm{Si}$ alloy. ${ }^{22}$
Table 2. Estimated values of critical grain size, $d_{c}(\mu \mathrm{m})$

\begin{tabular}{l|ccc}
\multicolumn{1}{c|}{ Alloy } & $23^{\circ} \mathrm{C}$ & $-78^{\circ} \mathrm{C}$ & $-196^{\circ} \mathrm{C}$ \\
\hline $\mathrm{Fe}$ & 3 & 27 & Very large \\
$\mathrm{Fe}-2 \% \mathrm{Ni}$ & 0.5 & 2 & 20 \\
$\mathrm{Fe}-1 \% \mathrm{Si}$ & 0.4 & 0.9 & 6 \\
$\mathrm{Fe}-1 \% \mathrm{Al}$ & 0.6 & - & $\geq 30$ \\
$\mathrm{Fe}-2 \% \mathrm{Ti}$ & $\sim 0$ & - & 2.5
\end{tabular}

Although detailed information on the interaction between $\mathrm{Si}$ atoms and interstitials is not available yet, some authors have pointed out that the presence of $\mathrm{Si}$ atoms in ferrite raises the temperatures at which stable and quasi stable carbides are formed. ${ }^{23)}$ Therefore, it is not unreasonable to assume that $\mathrm{Si}$ causes retardation of the segregation of carbon atoms to dislocations, namely the formation of Cottrell atmosphere, and thus the decrease in Lüders strain.

Accordingly, it can be considered that the $d_{c}$ values of the alloys in Table 2 are in the order of weakening interaction between interstitial and substitutional atoms.

However, it is not to be expected that large uniform elongation at low temperatures was attained only by the removal of interstitial atoms from matrix. This is suggested by the fact that decarburized Fe specimen having partially recrystallized structure was of a small elongation owing to plastic instability, and that the addition of $\mathrm{Al}$ which ties up $\mathrm{N}$ improved the ductility of ferrite only to a very limited extent. In addition, $\mathrm{Fe}-$ $1 \% \mathrm{Si}$ alloy with $0.1 \% \mathrm{C}$ was of nearly the same elongation as $\mathrm{Fe}-1 \% \mathrm{Si}$ alloy with $0.005 \% \mathrm{C}$.

It is well-known that at low temperatures a critical resolved shear stress of iron and its substitutional alloys varies according to the operative slip system, and that the ease of slip on (112) planes tends to decrease. On the macroscopic scale this is reflected on the appearance of slip pattern. ${ }^{25)}$ As the deformation temperature is decreased the slip pattern is changed in a different manner according to the kind of the solute element added to ferrite. In particular, the change of $\mathrm{Fe}-\mathrm{Si}$ alloy is reported to be remarkable, suggesting almost complete restriction of slip on (112) planes at low temperatures.

In the three dimensional polycrystalline aggregates individual grains have to deform under the constraint of surrounding grains. In this circumstance, if the number of operative slip systems is decreased, it will be more favorable to transmit strain to the neighboring grains than to accumulate it in the initially deformed grains. Suzuki ${ }^{5}$ has pointed out that the limited number of available slip systems is one of the important reasons why Lüders band does not appear in f.c.c. metals. Therefore, it is naturally expected that Lüders strain in b.c.c. metals will also be decreased, or even disappear, as in f.c.c. metals if the availability of slip systems are restricted for some reason or other. However, a further investigation of the slip mode of the alloys such as $\mathrm{Fe}-2 \% \mathrm{Ti}$ is required to make a definite conclusion.

As stated above, the worsening of ductility inherent 
in grain refinement of materials can efficiently be avoided by the addition of a certain substitutional element such as $\mathrm{Si}$ or $\mathrm{Ti}$.

\section{Conclusion}

(1) Unalloyed $\alpha$ iron $(\sim 0.01 \% \mathrm{C})$ having various microstructures developed by conventional cold rolling and subsequent annealing showed exceedingly poor ductility at low temperatures. At $-196^{\circ} \mathrm{C}$, specimens of grain size smaller than $\sim 20 \mu \mathrm{m}$ fractured by necking immediately after the yielding occurred, while specimens of grain size larger than that fractured intergranularly.

(2) The addition of $2 \% \mathrm{Ni}$ was found to be efficient in suppressing the intergranular fracture of specimens recrystallized into coarse grain size $(z 20 \sim$ $30 \mu \mathrm{m})$, although it was not efficient in suppressing the unstable necking for specimens of fine grain size $(\$ 20 \sim 30 \mu \mathrm{m})$.

(3) The addition of $1 \% \mathrm{Si}$ was found to be efficient in averting the plastic instability, thereby giving an appreciable amount of ductility to fine grained specimens. The addition of $2 \% \mathrm{Si}$ was as effective as $1 \%$ addition, while $0.5 \%$ addition was almost ineffective. The addition of Si was found to have no effect of suppressing the intergranular fracture for coarse grained specimens

(4) Good ductility of $\mathrm{Fe}-1 \% \mathrm{Si}$ at low temperatures was maintained over a wide range of carbon content, at least from 0.002 to $0.1 \%$. A weak tendency of ductility decrease was observed as carbon content was increased.

(5) Ti was found to have a similar effect of ductility enhancement as $\mathrm{Si}$, while $\mathrm{Al}$ was not.

(6) The Lüders strain of substitutional iron alloys studied was found to be smaller than that of unalloyed iron over a fine grain size range when compared at the same grain size and also at the same strength.

(7) The critical grain size $\left(d_{c}\right)$, at which Lüders strain exceeded uniform elongation and a transition occurred from stable to unstable plastic flow, was found to be increased as the deformation temperature was decreased. It was decreased by the addition of substitutional element. In particular, the decrease by $\mathrm{Si}$ or Ti was remarkable.
(8) Possible causes for the decrease in Lüders strain or $d_{c}$ were discussed. The change of slip mode which might be imposed by the presence of substitutional atoms is considered to be more important than the change of the distribution of interstitial atoms.

\section{REFERENCES}

1) W. B. Morrison and R. L. Miller: Ultrafine Grain Metals, ed. by J.J. Burke and V. Weiss, Syracuse University Press, (1970), 183.

2) W. B. Morrison: Preprint of 2nd Int'l Conf. Strength of Metals and Alloys, ASM, Asilomar, USA, (1970), 295.

3) V. Ramachandran and E. P. Abrahamson: Script. Met., 6 (1972), 287.

4) R. H. Goodenow and J.H. Bucher: Trans. ASME, 91 (1969), 603.

5) H. Suzuki: Tetsu-to-Hagané, 50 (1964), 2351

6) S. Takeuchi: J. Phys. Soc. Japan, 27 (1969), 929.

7) C. E. Lacy and M. Gensamer: Trans. ASM, 32 (1944), 88.

8) W. C. Leslie: Met. Trans., 3 (1972), 5.

9) W. P. Rees, B. E. Hopkins and H. R. Tipler: JISI, 177 (1954), 93.

10) R. Honda and H. Taga: Metal Sci. J., 2 (1968), 172.

11) J. Imamura, H. Hayakawa and T. Hayami: Tetsu-toHagané, 60 (1974), A 159.

12) K. Ota: Tetsu-to-Hagané, 28 (1941), 969

13) K. Ota: Tetsu-to-Hagané, 56 (1970), 110.

14) M. Enomoto and E. Furubayashi: Script. Met., 10 (1976), 717.

15) J. F. Butler: J. Mech. Phys. Solids, 10 (1962), 313.

16) J. F. Butler: Acta Met., 10 (1962), 258.

17) P. Abramowitz and R. A. Moll: Met. Trans., 1 (1970), 1773.

18) J. L. Jellison and N. S. Stoloff: Mater. Sci. Eng., 13 (1974), 231.

19) J. R. Low, Jr. and M. Gensamer: Trans. AIME, 158 (1943) 207.

20) W. C. Leslie and R.J. Sober: Trans. ASM, 60 (1967), 99.

21) H. D. Solomon, C. J. McMahon, Jr. and W. C. Leslie: Trans. ASM, 62 (1969), 886.

$22)$ T. Taoka, S. Takeuchi and E. Furubayashi: J. Phys. Soc. Japan, 19 (1964), 701.

23) W. C. Leslie: Acta Met., 9 (1961), 1004.

24) A. Matsuda and K. Nakajima: Tetsu-to-Hagané, 62 (1976), 652 .

25) S. Takeuchi, T. Taoka and H. Yoshida: Trans. ISIJ, 9 (1969), 105 